\title{
Por que as empresas saem de redes? Contribuições para formação, gestão e fortalecimento de redes interorganizacionais
}

\author{
Why do companies leave networks? \\ Contributions to formation, management \\ and strengthening of \\ interorganizational networks
}

\author{
LEANDER LUIZ KLEIN* \\ BRENO AUGUSTO DINIZ PEREIRA**
}

\section{RESUMO}

O objetivo deste trabalho é identificar quais fatores estão relacionados à saída de empresas de redes interorganizacionais. Para a consecução do objetivo proposto, foram selecionadas sete redes interorganizacionais que tiveram empresas se desligando delas, e por meio de entrevistas com os presidentes dessas redes foram coletados os dados para o presente estudo. Como procedimentos de análise dos dados, seguiu-se a técnica da análise de conteúdo. Os resultados mostram que um conjunto de fatores está ligado à saída de empresas de redes, entre eles, a falta de critérios para a seleção, a falta de comprometimento e confiança, atitudes oportunistas, custo da rede, o individualismo, o imediatismo por resultados e a falta de alcance dos objetivos. Como conclusão, tem-se que, mesmo que sejam claros os benefícios que as empresas podem ter atuando em conjunto, alguns fatores podem tornar negativa a relação custo $\mathrm{x}$ benefícios para os parceiros, que acabam por decidir sair da rede.

Palavras-chave: Redes Interorganizacionais. Problemas de Redes. Saída de empresas.

* Universidade Federal de Santa Maria - UFSM. Doutor em Administração. kleander88@gmail.com .

** Universidade Federal de Santa Maria - UFSM. Doutor em Administração. professorbreno@terra.com.br . 


\section{Abstract}

The objective of this study is to identify which factors are related to the withdrawn of firms from interorganizational networks. To achieve the proposed objective we select seven interorganizational networks were selected that all of those had companies leaving them, and through interviews with the presidents of these networks data were collected. As analytical procedures of these data, we followed the technic of content analysis. The results show that a set of factors is connected to companies leaving networking, among them: the lack of criteria for selection, lack of commitment and trust, opportunistic attitudes, network cost, individualism, immediacy of results and lack of achievement of goals. The conclusion has been that even if the benefits that companies may have when acting as a group are clear, some factors may become negative the cost vs benefit relation to the partners, who may decide to leave the network. Key-words: Interorganizational Networks. Network Problems. Withdraw of companies.

\section{INTRODUÇÃo}

Algumas estratégias há muito utilizadas pelas empresas não são mais vistas como uma vantagem competitiva e sim como um requisito para se manter no mercado, dado os desafios impostos pela crescente complexidade do mundo globalizado. Assim, as empresas precisam olhar além das fontes tradicionais de vantagens para obterem êxito frente à intensa competição. Diante disso, destaca-se a importância das empresas desenvolverem configurações estruturais mais dinâmicas, empreendedoras e competitivas.

As parcerias interorganizacionais, apesar de não serem recentes, são referendadas, em grande parte da literatura sobre o assunto, como uma forma adequada para as organizações se manterem competitivas no mercado, e como alternativa de crescimento. Sua importância é bastante visível no que diz respeito às empresas de pequeno e médio porte que, geralmente, têm mais dificuldades em agir isoladamente. $\mathrm{O}$ formato organizacional, em redes de empresas, está relacionado à complementaridade de competências, informações diversificadas e direcionadas, aprendizado e inovação (LIN et al., 2009), que podem diminuir a incerteza no mercado de atuação, 
suprir as necessidades de recursos das empresas parceiras em redes, e ser "uma importante fonte de geração de valor" (CORSTEN et al., 2011, p. 550). Nessas redes, as empresas parceiras trabalham em conjunto para desenvolver novos processos, produtos e tecnologias e executar outras tarefas, como programas de marketing, que uma empresa individual não poderia realizar por conta própria (CHASSAGNON, 2013).

As parcerias entre empresas são, geralmente, formadas quando duas ou mais organizações colaboram entre si para compartilhar recursos com um objetivo em comum para melhorar o seu desempenho em resposta a uma ameaça do ambiente para o seu desenvolvimento. Segundo Pereira e Pedrozo (2004, p. 70), “a formalização da cooperação entre duas ou mais organizações constitui-se numa decisão estratégica que visa dividir riscos, trocar recursos, acessar novos mercados, alcançar economias de escala, obter sinergias e, por fim, garantir vantagem competitiva".

Entretanto, atualmente, a estrutura e a gestão das redes levantam novas questões. Chao (2011) explica que a colaboração de empresas em redes pode ser vista como uma série de processos de tomada de decisão envolvendo a interação entre as firmas, na qual, a insuficiente compreensão ou a falta de comprometimento de uma das partes pode levar a uma variedade de erros e vieses, afetar a estabilidade do processo cooperativo, e, em alguns casos, a continuidade da rede. Aparentemente, se uma empresa sai de uma rede houve um problema na relação, pois, esse tipo de empreendimento não é formatado para que as empresas saiam, exceto que ela tenha prazo determinado de existência, situações essas que não são o foco deste estudo.

Tem-se verificado, empiricamente, que as redes trazem vantagens caso várias condições, muitas vezes interdependentes, sejam preenchidas, o que torna o processo de gestão/governança ainda mais complexo. Muitas redes não conseguem consolidar suas estruturas e seus modelos de gestão, pois aspectos e fatores negativos podem surgir nas relações a ponto de não compensar os investimentos efetuados, fazendo que as empresas saiam das redes. Estudos como o de Sheng-Yue and Xu (2005) ressaltam que a taxa de falência de redes, em geral, é superior a 50\%. Diante disso, questiona-se: 
se realmente as redes proporcionam benefícios e competitividade, por que algumas empresas se desvinculam delas? Quais as razões que levam a essa retirada? Por que elas saem? A resposta a essas perguntas é, justamente, o objeto que motiva este estudo.

Para Pesämaa (2007), muitas empresas não estimam as desvantagens/custos de se inserirem em redes, e não são capazes de avaliar se estão aptas a entrar nas redes, ou se tal estratégia é um bom negócio. A saída de uma empresa integrante de rede pode ser compensada, em termos de sua competitividade, com a entrada de outra empresa, mas essa "rotatividade" de empresas na rede causa dificuldades para o fortalecimento do grupo, levando a diminuir a otimização dos ganhos e do valor gerado às empresas parceiras. Dessa forma, este trabalho tem como objetivo identificar quais fatores estão relacionados à saída de empresas de redes interorganizacionais.

$\mathrm{O}$ estudo justifica-se por existir pouco conhecimento a respeito do tema, e por ser limitado o conhecimento sobre quais esforços e aspectos, quando e como eles são susceptíveis de conduzir ao bom desempenho de alianças colaborativas (CHEN, 2010). Assim, uma maior compreensão acerca do assunto, verificando os problemas que levam à saída de empresas parceiras de redes, pode auxiliar na resolução de problemas e dificuldades que surgem desde o processo de formação até o fortalecimento de redes, problemas esses, que impossibilitam o alcance das metas e objetivos estipulados. Acredita-se, também, que este artigo possa ter representatividade para a melhora da performance de redes de empresas e sua continuidade.

\section{REDES INTERORGANIZACIONAIS: CONCEITOS, CARACTERÍSTICAS E BENEFÍCIOS}

Na década de 90, Oliver (1990, p. 241) caracterizou as redes interorganizacionais como sendo "as transações relativamente constantes, fluxos e ligações que ocorrem entre e no meio de uma ou mais organizações em seus ambientes". As redes interorganizacionais, no entendimento de Wincent et al., (2014) são formadas em um ponto específico no tempo para realizar atividades específicas de rede e possuem limites claros para definir as empresas que são reconhecidas como membros da rede. Já para Verschoore (2004, p. 
25), uma "rede interorganizacional pode ser definida como a organização composta por um grupo de empresas com objetivos comuns, normalmente relacionadas, com prazo ilimitado de existência".

As redes de empresas, como uma configuração estrutural mais moderna e dinâmica, podem ser definidas como acordos duradouros entre duas ou mais empresas envolvendo a troca, o compartilhamento, ou codesenvolvimento de produtos, tecnologias e serviços (GULATI, 2007). Na formação de uma rede interorganizacional, Gulati e Gargiulo (1999) referem que ela se dá pelas diversas configurações verticais ou horizontais desenvolvidas pelas empresas que formam relacionamentos. Em muitos casos, a formação de alianças estratégicas envolve empresas que disponibilizam recursos complementares para suprir necessidades técnicas e de mercado. Nessa relação, há a troca de ativos tangíveis e intangíveis, o que gera novas competências e leva os agentes a um estágio de desempenho superior, inacessível até então (ZAWISLAK, 2000). Ressalta-se que há uma distinção entre redes horizontais e verticais, e, neste estudo, o foco se dirigiu às do nível horizontal, as quais englobam empresas de um mesmo setor que permanecem legalmente independentes e cooperam em aspectos predefinidos (WEGNER e PADULA, 2010).

As redes interorganizacionais viabilizam diversas ações, como compartilhar os riscos associados aos negócios entre todos os participantes (EBERS, 1999; SADOWSKI e DUYSTERS, 2008; MARIOTTI e DELBRIDGE, 2012), a racionalização de recursos, a partilha dos custos das atividades de marketing e comerciais (LAMB et al., 2008; MPOYI, 2003), a transferência de conhecimento (PHELPS et al., 2012; SCHULZ e GEITHNER, 2010), menores custos de transação e ganhos econômicos (WILLIAMSON, 1975; IRELAND e WEBB, 2007; VINHAS et al., 2012).

No entanto, alguns aspectos e fatores negativos podem surgir na relação entre empresas, a ponto de não compensar os investimentos realizados, e desestruturar a rede a partir da saída de alguns integrantes. Este assunto será abordado no item a seguir, onde se descreverá os principais problemas das redes de empresas, referendados na literatura sobre o tema. 


\subsection{Problemas de redes interorganizacionais}

Cooperar com mais empresas do mesmo ramo de atividade por meio de redes requer investimentos, tempo e recursos para a implementação e continuidade. Além disso, demanda o comprometimento das empresas parceiras para a manutenção de seu sistema de gestão e capital social, para que se possa coordenar a relação e gerar benefícios esperados. As redes interorganizacionais operam a partir de uma base de confiança, comprometimento e reciprocidade entre os integrantes, para que ocorram o acesso e o compartilhamento de recursos de forma sinergética, e, com isso, aumentar as suas capacidades de competir (FLEURY e OLIVEIRA, 2001). Sem comprometimento e confiança, entre os integrantes da rede, a possibilidade de ganhos conjuntos e de sucesso fica limitada.

Uma parceria mal gerida, em que não há motivação entre os parceiros envolvidos, está entre os fatores relacionados à saída de empresas de redes e o fracasso desse tipo de aliança estratégica (SADOWSKI e DUYSTERS, 2008). Outros fatores críticos também estão envolvidos, nesse processo, como pouca confiança (WELTER, 2012; BACHMANN, 2011), transferência de conhecimento (YAYAVARAM e AHUJA, 2008; CARDOSO et al., 2012; NICOTRA et al., 2014), aprendizagem (ENGESTRÖM e KEROSUO, 2007; HOBERECHT et al., 2011; SCHULZ e GEITHNER, 2010), comprometimento dos integrantes (CASTRO et al., 2011; PARAST e DIGMAN, 2008), a assimetria de informação (MISHRA et al., 1998; VENTURINI, 2008), oportunismo (WILLIAMSON, 1985; PEREIRA et al., 2010), custos da cooperação (ADLER e KWON, 2002; PESÄMAA, 2007) e inovação e geração de valor às empresas parceiras (PROVAN e HUANG, 2012; AHOLA, 2009; AHUJA et al., 2012).

Somam-se aos fatores supracitados a inflexibilidade de atuação dos agentes das redes em relação à área geográfica, ao acesso isolado a novos mercados e aos diferentes produtos comercializados pelas empresas parceiras em cada região ou cidade em que se situam. Além disso, um fator determinante para a longevidade dos relacionamentos está no fato de reconhecerem a existência de assimetria de incentivos em investir na relação, a qual inevitavelmente surge à medida que a aliança evolui. Objetivos que eram comuns podem, com o tempo, perder parte do sentido e, por conseguinte, reduzir o 
interesse de um ou de outro participante em cooperar (WEGNER et al., 2008). Associado a isso, a vantagem de uma empresa pertencer a uma rede tende a se extinguir com o tempo e somente o diferencial de pertencer a uma rede não é mais suficiente para lhe garantir a sustentabilidade (PEREIRA, 2005, p. 183).

No entendimento de Park e Ungson (2001), o oportunismo e a complexidade gerencial das redes são dois problemas ligados ao insucesso delas. Em redes, nas quais há o oportunismo, os autores mencionam que existirá dificuldade em coordenar as atividades coletivas e alcançar os objetivos dos associados. Langlois e Robertson (1995) afirmam que, ao longo do tempo, as próprias firmas participantes se alteram, modificando também os custos de transação e de governança da rede, fazendo que os limites e benefícios sejam dinâmicos.

A complexidade para coordenar novas transações e formas de atuação, como as redes, pode aumentar até o ponto em que o custo desse processo aumente e ultrapasse o benefício oriundo do empreendimento, não compensando sua manutenção. De forma a facilitar a visualização dos aspectos mencionados como problemas de redes de empresas, elaborou-se um quadro de referência que engloba os mesmos, e que servirá, posteriormente, para a análise dos dados empíricos coletados neste trabalho.

\subsection{Quadro de referência do trabalho}

Zineldin e Dodourova (2005) colocam que, em geral, os estudos sobre cooperação entre empresas falham em usar indicadores claros para distinguir sucesso e fracasso em alianças estratégicas. Embora não haja consenso quanto aos motivos que levam as empresas saírem da rede a qual pertenciam ou ao fracasso dela, os fatores que conduzem ao sucesso podem oferecer importantes indicativos. Nesse sentido, diferentes modelos teóricos e trabalhos foram consultados para constituir um quadro de referência para este estudo, como os de Sadowski e Duysters (2008), Chao (2011), Corsten et al. (2011), McCutchen et al. (2008) e Pesämaa (2007). Como base, foram tomados os modelos de Chen (2010) e Wegner (2011), seguindo as etapas da formação e desenvolvimento de redes. O quadro de referência proposto é esquematizado na Figura 1. 
Figura 1. Quadro de referência do trabalho

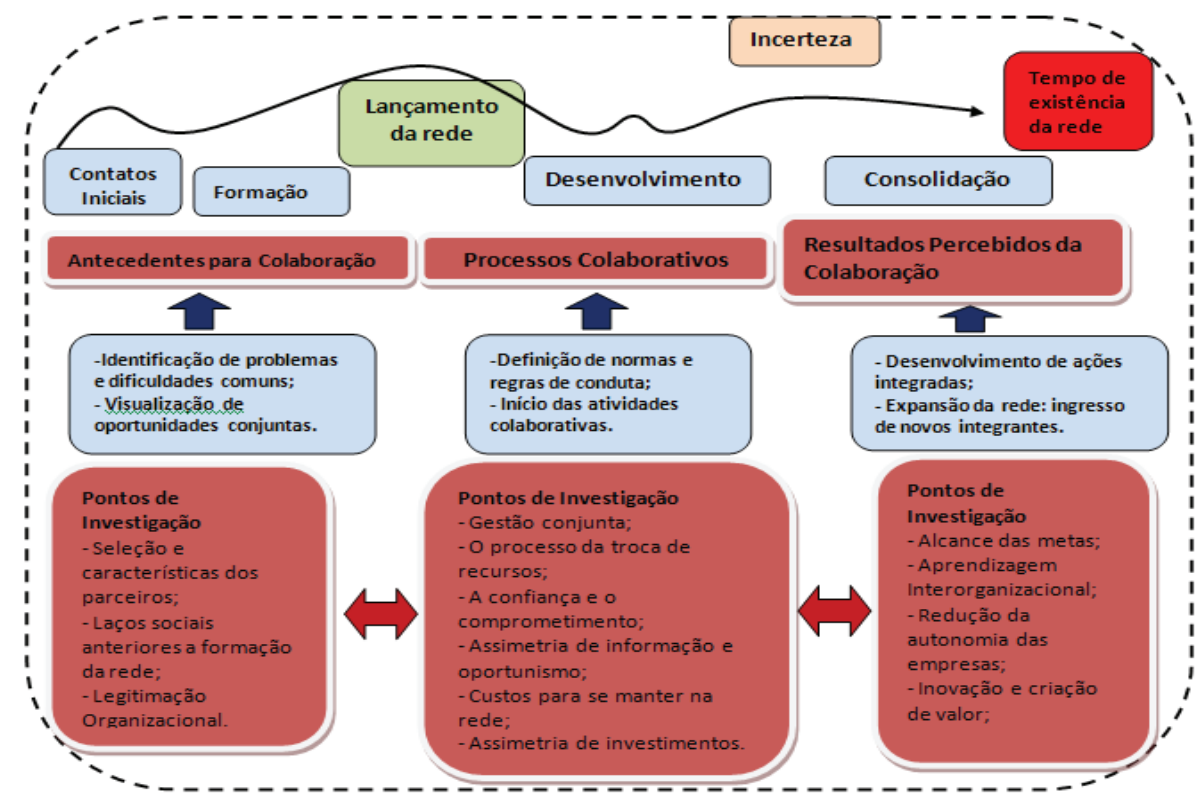

Fonte: Elaborada pelos autores

Os aspectos referentes ao primeiro estágio focam nos antecedentes à constituição da rede ou na sua formação e refletem nas fases seguintes e no fortalecimento da rede. Nessa fase, os aspectos investigados são: a seleção dos parceiros, os laços sociais anteriores à formação da rede e a legitimação organizacional. Os aspectos colocados no segundo estágio põem vista à colaboração como um processo dinâmico, em que os parceiros aumentam o compartilhamento de informações, recursos e o respeito mútuo (DOZ, 1996; OLIVER, 1990). Nessa etapa, julgou-se, a partir dos demais estudos, que o processo de colaboração é constituído por múltiplas dimensões, incluindo a gestão conjunta, o compartilhamento de recursos, a construção de confiança e do comprometimento, os custos para se manter na rede e a possibilidade de assimetria de investimentos e o oportunismo.

Pesquisas sobre o terceiro estágio identificam os principais resultados da colaboração, por exemplo, se a colaboração atingiu os seus objetivos e se resultou na melhoria da aprendizagem organizacional. 
Poucos estudos ligam antecedentes e precondições que motivam a formação de redes, os processos que se desenvolvem no estágio de desenvolvimento e os resultados finais de colaboração (BINGHAM e O'LEARY, 2008). No quadro de referência, estão alguns pontos a serem considerados para que as empresas tomem a decisão de fazer parte de uma rede interorganizacional e nela permanecerem ou não. Esses diversos aspectos têm influenciado a performance das redes interorganizacionais.

\section{MÉtodo do TRABALHO}

Este artigo caracteriza-se por ser um estudo exploratório, uma vez que se busca explorar e entender um problema em profundidade, avançar no conhecimento sobre o tema e ampliar estudos já existentes a partir de novas perspectivas e descoberta de novas relações, característica dos estudos exploratórios (SAMPIERI et al., 2006; SELLTIZ et al., 1972). Como estratégia de pesquisa, julgou-se adequada uma pesquisa com abordagem qualitativa, visto que o estudo acerca da problemática explorada neste artigo ainda não foi muito estudada. Além disso, a pesquisa qualitativa é uma forma adequada para entender a natureza de um fenômeno social e dá visibilidade ao assunto pesquisado por meio de um conjunto de práticas materiais e interpretativas (SAMPIERI et al., 2006; DENZIN e LINCOLN, 2006; RICHARDSON, 1999).

Como procedimentos de coleta de dados, efetuaram-se entrevistas semiestruturadas com presidentes de sete redes de empresas de diferentes ramos de negócio que tiveram empresas saindo das mesmas. Foram realizadas sete entrevistas pelo fato de estudiosos de pesquisa qualitativa indicarem como número ideal de entrevistas entre quatro e dez, sendo que o pesquisador deve ter a sensibilidade em verificar quando as respostas dos respondentes estão praticamente se repetindo e nada mais de novo está sendo coletado (EISENHARDT, 1989). A escolha das redes selecionadas para realizar este estudo procedeu-se de maneira intencional, por conveniência, pela facilidade de realização das entrevistas e adequação ao estudo. Essa forma de seleção supõe um procedimento de seleção informal (SAMPIERI et al., 2006). 
O instrumento de coleta de dados utilizado foi a entrevista semiestruturada. Julgou-se apropriado esse instrumento porque ele permite investigar o tema com mais detalhes por possuir uma estrutura flexível composta por questões abertas na área a ser explorada (BRITTEN, 1995). O instrumento foi construído por meio de perguntas abertas, seguindo os fatores espostos no quadro de referência do trabalho exposto na Figura 1.

As entrevistas foram realizadas no lugar em que os presidentes das redes tinham disponibilidade, alguns em seus locais de trabalho e outros em suas respectivas residências. Os entrevistados foram denominados, para fins de análise de suas falas, como E1, E2, E3, E4, E5, E6 e E7, respectivamente. As entrevistas foram gravadas e atingiram a duração de cerca de 60 minutos. Elas foram transcritas para posterior análise.

A análise dos dados foi realizada por meio da técnica da análise de conteúdo. Optou-se por essa técnica porque ela parte de procedimentos sistemáticos e objetivos de descrição dos relatos dos entrevistados para a busca de indicadores sobre o que está por trás da fala. Com ela se pode verificar a similaridade das falas dos entrevistados (BARDIN, 2010). Foram constituídos dois tipos de categorias de análise: 1) a priori - constituídas a partir do quadro de referência deste artigo; e 2) não a priori - desenvolvidas com base nas falas dos entrevistados, a partir da similaridade dos relatos. Os resultados obtidos são descritos e discutidos nas seções seguintes do presente trabalho, nas quais são apresentados os indicativos desta pesquisa acerca do tema proposto.

\section{Apresentação dos resultados}

\subsection{Categorias de análise}

Nesta seção, são analisadas as categorias de análise definidas $a$ priori conforme o quadro de referência apresentado na Figura 1, e a categoria não a priori constituída a partir dos relatos dos entrevistados, por meio da codificação dos elementos por analogia (BARDIN, 2010). Buscou-se, com isso, aproveitar todas as informações obtidas com as entrevistas para encontrar os principais fatores que levam as empresas desistirem do processo de cooperação e saírem das redes. 


\subsubsection{Antecedentes para colaboração}

A decisão do gestor de uma empresa firmar parceria com outras empresas pode ser influenciada pela dificuldade de encontrar parceiros, denominada como "imperfeição do lado da oferta" por Van Slyke (2007). Graddy e Chen (2006) observaram que, mesmo se as organizações estavam dispostas a cumprir com as exigências de financiamento e outros requisitos para formar uma rede, elas eram limitadas pela sua capacidade em potencial.

Hitt et al. (2000) sugerem a seleção de parceiros como fator determinante de sucesso da aliança devido à necessidade de alinhamento de recursos específicos e a continuidade da troca entre eles. Aparentemente, um dos aspectos que estão relacionados com a saída de integrantes das redes é que não havia critérios claros e definidos para a seleção dos integrantes da rede. $\mathrm{O}$ objetivo, nesse instante, parecia simplesmente o de formar a rede. Os trechos dos relatos de E2 e E4 evidenciam esse problema.

Olha, só sei que a gente recebeu convite para participar, e iam se convidando as pessoas, as empresas, e elas aceitavam. Elas tinham o interesse em participar, e daí um avisava o outro e a rede foi aumentando. Não tínhamos critérios. (E2)

Não. Entrava quem queria, mas que fosse sério. A padaria de uma cara lá, na época lá, não tinha muita inadimplência, ele ta pagando os fornecedores, ele tem um nome? Está bem, vamos convidar ele. No começo, colocávamos quase todos que se podia, e depois tirávamos quem não queríamos. (E4)

Quando não existem critérios para a seleção dos integrantes, podem ocorrer problemas na relação quanto ao cumprimento dos acordos e contratos efetuados em rede, muitas vezes simplesmente pela diferença no tamanho (capacidade econômica, competitividade no mercado etc.) das empresas selecionadas. Muitas empresas entram em redes sem ter condições de cumprir, por exemplo, com uma meta de compras estabelecida, o que influencia na parceria com os fornecedores e no nível de confiança entre os integrantes da rede. 
Outro aspecto refere-se à importância dos integrantes da rede se conhecerem antes da formação dela. Gulati (1995) argumenta que a capacidade de uma organização para aderir a uma aliança é limitada pela sua rede social. O complexo de relações entre membros de um sistema social de diferentes dimensões, recursos e habilidades designa a possibilidade de formar uma relação. Os entrevistados, quando questionados a respeito do fato de conhecerem os demais integrantes anteriormente à formação da rede e quanto isso facilitava a gestão e a organização da mesma, tiveram respostas diferentes. As falas de E1 e E7 ilustram essa diferença.

Eu acredito que sim, que isto influencia, porque isto também é uma questão de confiança e credibilidade. Eu acredito que isto talvez foi um dos principais entraves da nossa rede, pois como as pessoas não se conheciam, passaram a ter que trocar informações com outras pessoas, e como essas pessoas não eram conhecidas do dia-a-dia, houve talvez muita desconfiança de passar dados para os outros e as pessoas acabaram retendo informações que eu acho que são importantes para o crescimento da própria rede. (E1)

Eu acho que o fato delas se conhecerem ou não antes da formação, isso não interfere viu. A única coisa pra formação é que o possível associado tem que ter é vontade, participar, querer e ter o espírito do cooperativismo, se não ele vai trancar o processo. As redes só acontecem quando seus associados querem que aconteça e fazem ela acontecer. Por que se entra alguém na rede com a estrutura que ela tem, e o cara não está aberto às mudanças, ele vai acaba ficando de fora do negócio. (E7)

O fato de os integrantes se conhecerem antes da formação da rede foi destacado como importante por outros dois entrevistados, os quais alegaram que isto, além de ter relação com a confiança e o nível de trocas dos agentes da rede, facilitava também o processo de formação da mesma. A aparente desconfiança na troca de informações em face de os integrantes não se conhecerem, mencionada por E1, não foi vista como uma dificuldade ou algo que influenciasse na saída de empresas da rede, pelos demais entrevistados, pois estes 
mencionaram que a rede precisa de um tempo de amadurecimento e que, aos poucos, aumentaria a confiança e faria que o medo de trocar informações e expor novas ideias no grupo desaparecesse.

Quanto ao aspecto da legitimidade, todos os entrevistados mencionam que uma marca própria da rede aumenta a legitimidade das empresas integrantes e não interfere na saída de empresas das redes às quais pertenciam.

\subsubsection{Processos colaborativos}

O que diferencia a gestão de redes de empresas da governança corporativa é que os atores são as empresas e não indivíduos. Em uma rede cooperativa, a gestão é o resultado de um processo de negociação entre os respectivos dirigentes das empresas participantes no acordo (WEGNER e PADULA, 2010). Referente à gestão conjunta da rede, que envolve o sistema de regras criadas pelo grupo e a forma como as decisões eram tomadas; e à troca de recursos, que se refere às capacidades, habilidades complementares e troca de novas tecnologias ou mercados, os entrevistados mencionaram que a falta desses aspectos não interferiu na saída de alguns integrantes das redes, motivo pelo qual não carece de análise mais profunda neste trabalho.

Um fator citado pela maioria dos entrevistados como determinante para a saída de integrantes da rede foi a falta de confiança. Esse aspecto influencia na administração da rede, no "abrir o jogo" em reuniões entre os associados, na execução de uma atividade ou projeto conjunto, no fortalecimento das negociações diante dos fornecedores, na diminuição da assimetria de informações e do oportunismo, e na própria continuidade da rede. Para Bachmann et al. (2001), sem um mínimo de confiança é quase impossível o estabelecimento e a manutenção de relações organizacionais bem-sucedidas por um longo período. A falta de confiança, vista como um problema pela maioria dos entrevistados, pode ser confirmada pelas falas de E3 e E4.

Sim, a confiança foi um problema já, às vezes. Dos associados em geral, alguns saíram por não ter confiança. Um é o caso de um associado que entrou novo, não tinha essa questão associativista e achava 
que em todas as negociações que nós fazíamos, que tinha que ter uma condição melhor. Então trancava o processo, e não deixava o grande grupo negociar. Acabava se perdendo todo o tempo, toda a energia que a gente gastou no processo. (E3)

Sim, a falta de confiança era uma questão. Por que assim, sem confiança não dá pra trabalhar. É que eu não trabalho com quem eu não possa confiar. A pessoa tem que ser confiável, tem que ter uma postura correta que eu possa confidenciar dados para ela e ela para mim, isso é confiança. Que não vai haver trairagem. Mas a tua pergunta se foi se isso influenciou na saída? Sim, foi isso. (E4)

Com a confiança, o comprometimento é citado como um dos mais importantes fatores para a formação e manutenção do relacionamento interorganizacional. Sem o comprometimento, cria-se dificuldades para a aproximação entre os empresários pertencentes à rede, à reciprocidade com o próximo e às obrigações individuais, como a participação nas reuniões, o cumprimento dos acordos efetuados e demais atividades conjuntas. A falta de comprometimento pode levar muitas empresas a desanimarem ou desistirem da cooperação por estarem trabalhando pelos outros. Nas falas dos entrevistados, pode-se verificar que a falta de comprometimento de alguns integrantes era um problema e estava relacionado com a saída de alguns integrantes. Os trechos dos relatos de E1 e E2 permitem visualizar essa questão.

Um grande problema na nossa rede é sim essa questão do comprometimento. Você define quem é responsável pela expansão, monta a estrutura e o que tem que fazer, só que isto não acontece. Se o presidente não puxa a frente ou a executiva, e às vezes mesmo puxando, as pessoas sempre tem uma desculpa. Pra jogar futebol eles têm tempo, mas agora para vir pra uma reunião de diretoria, pra fazer uma visita para um futuro associado, eles não têm. (E1)

Não existia o comprometimento de todos, muitos estavam na rede por estar e iam de carona. Muitos achavam que a rede é a salvação para os problemas que a empresa tem. Tinham muitos que não tinham crédito 
no mercado, e... entende. Daí, essa parte do comprometimento era um problema para rede. E também assim, outra coisa as pessoas não gostavam muito de estar indo nas reuniões, e se deslocar, acabavam saindo por causa disso, achavam as coisas muito burocráticas. (E2)

Outra questão problemática no processo cooperativo está relacionada ao oportunismo de um ou mais de um integrante da rede, que envolve a quebra de acordos, normas e princípios que guiam a rede e a assimetria de informações. A atitude oportunista geralmente é motivada pela possibilidade de ganhos num prazo mais curto, ou até de imediato, em detrimento de ganhos futuros, o que impacta na confiança do grupo, aumenta a dificuldade de gestão e coordenação das atividades e gera um ambiente de incerteza na rede. Nas falas de E4 e E6, pode-se verificar situações oportunistas.

Saiu gente por ser oportunista. Uma situação, por exemplo, que um associado, ele aproveitou a confiança de outro associado para visitar a padaria do cara e descobrir coisas que ele não sabia. Ele foi abrindo geladeira e tudo mais. Ele entrou na empresa do cara, quando o empresário não estava, com os funcionários só, e aproveito a amizade do cara para ver as coisas, que ele achava que podia ver. Ele quebrou a confiança. Também teve aquele fato que não cumpriram o acordo com o fornecedor, que te falei antes. (E4)

Nós tivemos, tivemos. Um exemplo de oportunista e que foi aonde desencadeou um processo de expulsão dela, que foi com um associado de Cerro largo, que ela aproveitou a rede, começou a fazer produtos, que como ela tinha farmácia de manipulação e 'farmaco', ela aproveitou pra fazer produtos de manipulação e botar o nome da rede, vender como se fosse a rede que estava vendendo. E isso na rede era proibido. E aí nós acabamos desligando, fazendo o desligamento dela. (E6)

O oportunismo relaciona-se indiretamente com os custos das redes. Yu e Chen (2013) explicam que quanto menor o potencial para diminuir o oportunismo, tanto mais elaborados devem ser os mecanismos de governança e mais altos os custos envolvidos nas 
relações. Os custos para se manter na rede, com os quais as empresas pertencentes à rede devem se comprometer e investir, também foram um fator crítico citado pelos entrevistados. Geralmente, uma empresa permanece em rede se os custos para isso se mantiverem inferiores aos retornos ou ganhos obtidos por permanecer na rede, ou seja, se a relação custo $x$ benefício for positiva. Nas falas dos entrevistados, pode-se perceber que o motivo para alguns dos empresários desistirem do processo de cooperação é por eles julgaram altos os custos das redes e por não visualizarem ganhos que compensassem os investimentos feitos para se manter na rede. Os trechos dos relatos de E1 e E5 exaltam essa situação:

Os empresários saíram porque não sentiram vantagem em estar na rede. Eles tinham que pagar uma mensalidade. Como, às vezes, tinham compras não tão volumosas e por ser uma rede pequena, os descontos que conseguimos negociar não eram tão volumosos, então eles faziam o cálculo que, 'ah eu estou pagando tanto e estou ganhando tanto' e pensavam que não compensava permanecer na rede. E aí as pessoas acabaram se desmotivando, porque tinham uma mensalidade pra pagar, tinham que vir uma ou duas vezes por mês pra reunião e às vezes tinham que se deslocar, o que gerava custo. Daí as coisas não evoluíam, acabavam não gostando mais e pediam pra se retirar. (E1)

Como comentei contigo, temos mercados de pequeno porte, pequeno e médio, e como as distâncias eram grandes, dentre outras coisas também, alguns achavam que não estavam tendo um benefício muito grande em estar na rede, com as despesas que tinham. Os integrantes alegavam ao sair da rede, que não deu o retorno que eles achavam que iam ter. (E5)

Isso corrobora os postulados de Park e Ungson (2001, p. 47), que afirmam que "uma rede está apta a sustentar sua estrutura e permanecer como um mecanismo eficiente para transações inter firmas, enquanto os benefícios econômicos dos parceiros se sobrepuserem aos custos potenciais de gerenciar a aliança". 


\subsubsection{Resultados percebidos da colaboração}

Nesta parte do trabalho, quatro aspectos de eficácia percebida da colaboração foram analisados. Entre esses aspectos, apenas um deles, que se refere ao não alcance das metas e objetivos propostos, foi citado pela maioria dos entrevistados como fator que influencia na decisão das empresas saírem das redes. Os outros três aspectos, a falta de aprendizagem interorganizacional, a diminuição da autonomia das empresas parceiras e a falta de inovação e geração de valor, não foram vistos pelos pesquisados como problemas relacionados ao objeto deste estudo.

Com relação ao alcance dos objetivos, estudos como os de Pereira e Pedrozo (2004); Wegner e Padula (2010) sugerem que em redes interorganizacionais deve haver um alinhamento de objetivos, bem como, o alcance dos mesmos, para a continuidade da cooperação. Neste estudo, de maneira específica, pode-se verificar a partir da fala de alguns entrevistados que os objetivos inicialmente propostos quando da formação da rede não estavam sendo alcançados. A insatisfação e o descontentamento de algumas empresas parceiras com relação aos objetivos não atingidos passaram a incitar a saída das mesmas das redes. Isto pode ser verificado nas falas de E1 e E6.

Aconteceu sim. Na prática a formatação da rede, quando nos reunimos, foi vendida uma ideia no início, e depois aconteceu outra coisa. No início a própria universidade nos apresentou uma proposta de futuro, de crescimento e pra mim esse foi o grande erro. Todo mundo entrou achando que ia ganhar muito dinheiro logo. E uma rede de cooperação é uma coisa que tu tem que te doar pra ganhar dinheiro a médio e longo prazo, mas tem que ter a cooperação de todos. (E1)

No início estavam sendo atingidos. Nós passamos praticamente dois anos atingindo os nossos objetivos. Do segundo para o terceiro ano, que começou a vir essas grandes redes para o interior, e os nossos objetivos, nós não conseguimos mais atingir. Nós tínhamos metas, nós fazíamos metas. Metas trimestrais, semestrais e anuais. Mas, nós começamos a não atingi-las e aí começou a criar um descontentamento. E aí começaram a sai da rede e a rede acabou fechando. (E6) 
Verificam-se duas situações nas falas citadas, a primeira relacionada à falha na formulação dos objetivos quando da formação de rede, onde foram propostos objetivos que a rede poderia não alcançar, aparentemente, para atrair um maior número de empresas interessadas. Outra situação que levou ao não alcance dos objetivos e metas está relacionada a fatores externos, como o aumento da competitividade pela vinda de outras empresas e redes do mesmo ramo. No último caso, mesmo que as redes mantenham seus descontos com fornecedores, sua competitividade diminui, visto o ingresso de novas empresas que podem ter ofertas e preços menores. Assim, a falta de alcance dos objetivos e metas propostos em rede, que gerassem resultados que compensassem os investimentos feitos, está ligada à saída de empresas.

\subsubsection{Perfil individualista dos associados e imediatismo por re- sultados}

A gestão e a organização de redes requerem a estruturação de processos e práticas de gestão que possibilitam que os objetivos sejam alcançados e satisfaçam as expectativas dos integrantes. No entanto, muitas vezes os empresários querem ver os resultados imediatamente, e não compreendem que é necessário um tempo de maturação para a consolidação do grupo. Wegner e Padula (2012) também destacam o imediatismo por resultados como um dos problemas das redes de empresas, e que está relacionado com a saída de integrantes e com o fracasso de redes de empresas.

Em muitas redes, os resultados começam a aparecer a médio e longo prazo, necessitando de um tempo para a organização e programação das atividades conjuntas. Muitos aspectos legais, estatutários e concernentes às normas e procedimentos de gestão necessitam ser discutidos antes de se iniciarem as ações conjuntas propriamente ditas, o que não gera resultados de curto prazo. No entanto, na fala dos entrevistados verificou-se que o imediatismo por resultados é um problema para redes de empresas, e está relacionado com a saída de integrantes das redes, uma vez que estes empresários desejavam resultados de curto prazo ou mais rapidamente, e acreditavam que a rede poderia ser a solução dos seus problemas. Este fato pode ser visualizado nas falas de E5 e E7. 
...Então muitos associados às vezes acabam entrando com aquela euforia, expectativa de que num ano resolvo todos meus problemas. $\mathrm{Na}$ realidade não é assim. Por isso que, muitas vezes, alguns mercados de fora acabam procurando a rede, acabam entrando na rede e ficaram só 6 meses, 1 ano ou 2 anos, e aí acabaram saindo, pelo imediatismo. É por um problema de achar que ia resolver seu problema à curto prazo. (E5)

Olha, no nosso caso, quase que a rede não se formou pela questão do imediatismo. Na formação da rede, a gente quase arrancou os cabelos do consultor por causa de resultado, tipo 'quando vamos ganhar alguma coisa' [...] lá na formação, bah, os cara tem que ter paciência, por que se não, não se forma uma rede. E se o cara pensar em formar uma rede, e pensar que em 30 dias vão estar comprando ou fazendo qualquer outra coisa junto, daí vai se complicado, o negócio está fadado a não evoluir, e quem for imediatista vai querer sair. (E7)

Outra característica negativa para a coordenação e gestão de redes refere-se à tradicional atitude individualista de empresários. Muitos empresários, apesar de constituírem redes interorganizacionais, apresentam o perfil individualista, defendendo seus interesses individuais em detrimento do coletivo e, dessa forma, por não ser esse o ambiente da rede, acabam saindo. Na opinião coletiva dos entrevistados, o individualismo foi considerado como restritivo à permanência das empresas em redes. As falas de E3 e E6 exemplificam esse aspecto.

Se a pessoa não tem o pensamento associativista, a primeira coisa é ver se o cara fala muito "eu, eu e eu", daí esse cara não tem perfil. Mas se ele falar "nós, nós vamos fazer, eu penso que nós poderíamos...", aí essa pessoa tem perfil associativista. Muitas vezes a gente não consegue fazer o que a gente quer, mas a gente aos pouquinhos vai plantando a semente da rede, e daí a gente consegue almejar a nossa percepção, e esse é o trabalho de uma rede. O cara que se associa só por se associar, não está nem aí para as ações da rede, ele não vai se manter na rede. (E3) 
$\mathrm{O}$ individualismo não pode existir dentro de rede, entendeu? $\mathrm{Na}$ rede, a palavra chave é nós, a palavra chave é nós. Nós vamos fazer, nós vamos construir, nós vamos ter objetivos, porque se o presidente começar a dizer: "ah porque eu vou fazer desse jeito, eu vou tomar a decisão assim", entendeu? O associado vai se sentir no direito de também pensar na maneira que ele acha que deve fazer. Então a palavra na rede é o coletivo é nós, nós podemos, nós vamos, a rede vai fazer, nós vamos tomar a decisão. Se for no individual, com certeza não funciona. (E6)

Pode-se perceber que, para estar em rede as empresas integrantes devem pensar em ganhos coletivos, ganhos para o grande grupo. As empresas que pensarem de forma individual dentro da rede acabam ficando isoladas e não visualizando grandes vantagens para a sua empresa, e assim acabam se retirando da rede. Vale ressaltar que se associar a uma rede é um desafio, e para obter retornos mais significativos nesse tipo de associação, a visão individualista deve se superada e substituída por uma visão coletiva, que envolve um relacionamento aberto com outros empresários e a participação conjunta na tomada de decisões e busca de objetivos e metas comuns.

\subsection{Discussão dos Resultados}

A constituição de redes interorganizacionais surge, conforme discutido no início do trabalho, do interesse de um grupo de empresas que detenham alguns objetivos comuns, em obter uma vantagem competitiva e alcançar uma relação de custo x benefício favorável à sua permanência na rede. Na medida em que essa relação torna-se desfavorável e as empresas participantes não visualizarem ganhos futuros e a possibilidade de geração de valor, elas passam a questionar a formação do grupo (rede) e sua forma de organização. Como já visto, a partir dos resultados obtidos com as entrevistas, diversos fatores dificultam a sinergia do grupo, levando ao descontentamento de algumas empresas e sua consequente saída da rede. A Figura 2 permite visualizar esses principais fatores. 
Figura 2: Síntese dos fatores que influenciam na saída de empresas de redes

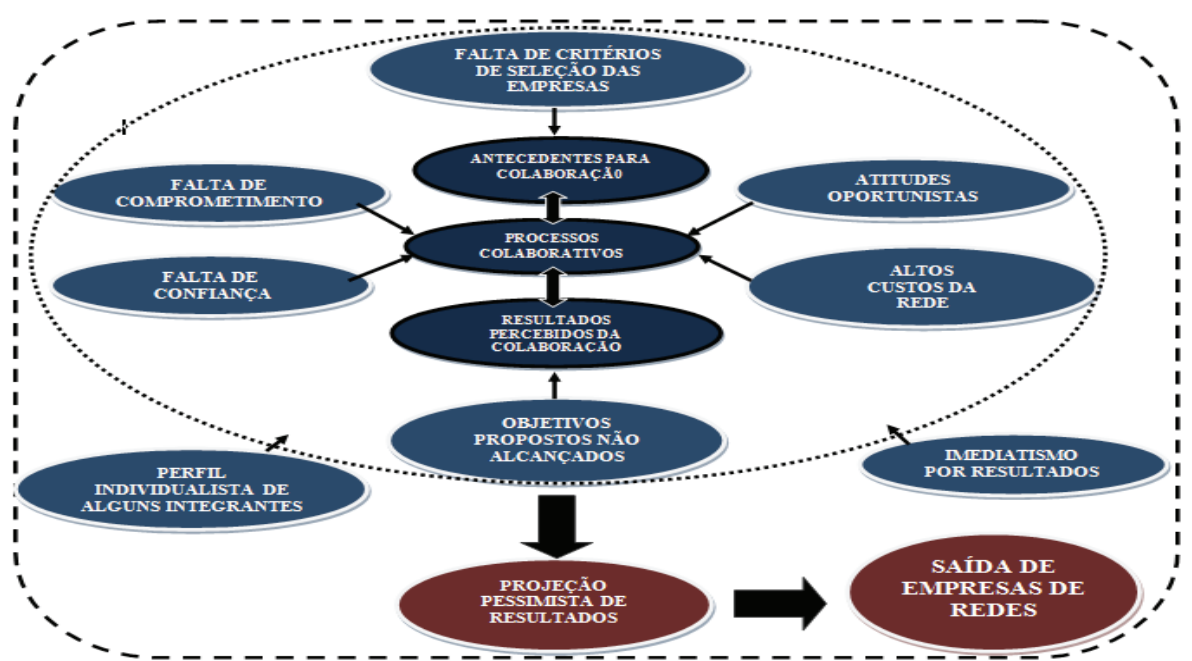

Fonte: Elaborada pelos autores

A Figura 2 mostra a interligação entre os três "estágios" das redes interorganizacionais, conforme o quadro de referência do trabalho, bem como, a influência de um sobre o outro. A partir dessa ligação, pretende-se evidenciar que o conjunto de fatores identificados nas categorias de análise como problemas de redes de empresas está relacionado entre si, e que isso levou os empresários a terem uma projeção pessimista de resultados futuros que compensassem a sua permanência na rede e saíssem dela.

Primeiramente, ressalta-se a aparente falta de critérios para a formação das redes pesquisadas. A inobservância a critérios como a complementaridade, a cultura, a situação financeira e o tamanho das empresas interessadas em constituir a rede pode gerar dificuldades para a gestão da rede e alcance dos objetivos e resultados pretendidos. Nesse sentido, Mays e Scutchfield (2010) exploram o que eles chamam de pré-requisitos para a colaboração, e explicam que o sucesso das parcerias entre empresas está relacionado a esses requisitos e à complementariedade entre as organizações que colaboram.

Diante disso, em alguns casos, por mais interessados e comprometidos que os proprietários das empresas demonstrem estar, 
a capacidade de suas empresas em participar de uma rede pode ser limitada, e não foi devidamente avaliada quando da seleção. Pode ocorrer também de uma empresa estar em um patamar mais avançado em relação às demais, não havendo assim congruência quanto aos objetivos pretendidos para atuar em rede.

O fato de algumas redes não alcançarem os objetivos propostos foi também um problema destacado por alguns entrevistados, principalmente em relação ao que foi comentado entre os participantes quando da formação da rede. Pode-se verificar que fatores externos como mudanças no mercado e a rivalidade de outras empresas concorrentes dificultaram o alcance dos objetivos. Popp et al. (2014) indicam que as atividades realizadas na fase inicial de formação da rede, e durante o seu desenvolvimento, vão afetar a maturidade da rede e como elas conduzem aos resultados esperados e à sustentação da rede ao longo do tempo. Dessa forma, o fato de pertencer a uma rede não se torna mais um diferencial que gera uma vantagem para as empresas integrantes, fazendo que elas saiam.

A ansiedade por resultados também é outro problema, e que está relacionado com a percepção de alguns empresários que os objetivos propostos não foram alcançados. Popp et al. (2014) explicam que, muitas vezes, há uma expectativa das empresas por resultados imediatos da rede e que ela demonstre o seu valor. Mas eles afirmam que essa é uma tensão que deve ser administrada pela rede, buscando um balanceamento entre os resultados da rede e a tolerância dos membros. Estes devem entender que a rede necessita de um tempo de amadurecimento, o que implica poucos resultados imediatos. A permanência das empresas e a continuidade da rede ocorrem, assim, em função do caráter motivacional dos integrantes. Essa discussão vai ao encontro dos achados de Raab et al. (2013), que salientam que as redes levam um longo tempo para se organizarem efetivamente e obterem resultados visíveis.

De maneira semelhante, o que afeta a permanência de determinados integrantes na rede é o perfil individualista que estes apresentam. O individualismo é explicado por Oyserman et al. (2002) como sendo uma visão que centraliza o pessoal, o individual - os objetivos pessoais, a unicidade pessoal e o controle pessoal - e que secundariza o social, o conjunto. Essa visão vai contra os postulados 
da ação colaborativa, que focaliza o conjunto, o grupo. O empresário que pensar de maneira individual, buscando satisfazer os seus interesses individuais em detrimento do bem coletivo, dificilmente permanecerá na rede, pois não é esse o propósito e o ambiente no qual uma rede atua.

O pensamento individualista pode ser relacionado com atitudes oportunistas dos empresários que pensam dessa forma. Geralmente, empresários com perfil individualista buscam formas e oportunidades específicas de ganhos para a sua empresa, mesmo que em detrimento do grupo. O oportunismo também foi ressaltado por alguns entrevistados e se pode perceber que algumas pessoas quebravam os contratos efetuados pelo grupo, por alguma oportunidade que tinham fora da rede. Também acontecia de muitas empresas usarem o parceiro como meio de se promoverem no mercado, sem haver o processo de troca. Esses resultados deste artigo corroboram os postulados de Provan e Skinner (1989), que descrevem como ações oportunistas a quebra de promessas, tomar atalhos para ganhos individuais, ser desonesto para obter vantagens e mascarar atividades inadequadas. Nesses casos, porém, geralmente a rede é que exclui esses associados.

Outro fator negativo citado pelos entrevistados foi a falta de comprometimento de alguns integrantes, tanto para a participação nas reuniões quanto nas atividades conjuntas efetuadas pela rede, principalmente nos acordos feitos com os fornecedores. Andrésen et al. (2012) definem o comprometimento como a fidelidade das empresas parceiras para atividades propostas e exercidas na rede e mencionam que há uma clara necessidade de comprometimento para realizar os processos e atividades em redes e atingir resultados positivos. Quando o parceiro não despende esforços para que o empreendimento conjunto tenha sucesso, o fortalecimento do grupo fica prejudicado, e pode ocorrer da rede excluir esse integrante.

Os aspectos já citados acabam por gerar certa desconfiança entre os parceiros e, com isso, a execução de atividades, geralmente, passa a ser realizada de forma mais burocrática, com contratos e termos de compromisso, que aumentam os custos de transação. Welter (2012) explica que a confiança que uma empresa deposita no outro parceiro gera sinais de reciprocidade entre as partes e aumenta a 
possibilidade de retornos positivos advindos da colaboração, sem a necessidade de controle efetivo das atividades. A falta de confiança entre os parceiros do grande grupo também foi visualizada nas falas dos entrevistados. Isto prejudica a atuação das empresas em rede, seja para realizar alguma atividade conjunta, seja na interação e na troca que pode haver entre os parceiros.

Por fim, ressalta-se o fato de que muitos empresários consideravam que os custos da rede eram altos e não superavam os ganhos e retornos obtidos pela atuação em rede, e assim optavam por sair. Todos os aspectos citados levam à deterioração da rede, incidindo na redução das atividades e oportunidades conjuntas e diminuição da relação custo $\mathrm{x}$ benefício.

\section{CONSIDERAÇões FINAIS}

O artigo aborda um aspecto pouco explorado nos estudos sobre cooperação interorganizacional: os motivos que levam as empresas a saírem de redes. As parcerias tomam suas formas na tentativa de diminuir a vulnerabilidade das empresas, que reconhecem suas limitações em agir isoladamente. Entretanto, pode-se observar na literatura a respeito do tema, tanto sob o enfoque dos paradigmas racional e econômico quanto do paradigma social, que fatores relevantes como a seleção de parceiros, o comprometimento, a confiança, os investimentos realizados pelos integrantes, estão relacionados à organização de redes. Esses fatores, entre outros, quando não são devidamente analisados e geridos, podem proporcionar dificuldades para a gestão e, em alguns casos, influenciar na permanência de empresas em rede.

O objetivo deste estudo foi o de identificar quais fatores estão relacionados à saída de empresas de redes interorganizacionais. Para tanto, realizaram-se entrevistas com presidentes de redes, e se identificaram diversos aspectos/fatores por meio da codificação das falas dos entrevistados. Em resposta aos questionamentos da pesquisa e ao objetivo do trabalho, destacam-se que nas redes estudadas diferentes fatores estão relacionados à saída de empresas, entre eles, a falta de critérios objetivos para a seleção dos futuros parceiros, a falta de comprometimento e confiança, o oportunismo e o individualismo de alguns integrantes, o fato de os objetivos pro- 
postos não estarem sendo alcançados, o imediatismo por resultados e os custos da rede.

Ressalta-se que o presente trabalho não busca ser normativo, no sentido de indicar categoricamente os aspectos/fatores que levam as empresas a saírem das redes. $\mathrm{O}$ artigo verificou alguns fatores que, na percepção dos entrevistados, influenciam na saída de empresas, buscando contribuir com a literatura sobre redes, sugerindo aspectos relevantes, que necessitam de atenção na formação, na gestão e no fortalecimento de redes. Revisar periodicamente a forma de organização e gestão da rede, quanto a processos decisórios, o envolvimento e as percepções dos integrantes, e o desenvolvimento de metas e objetivos, pode contribuir para o alinhamento das atividades desenvolvidas e os interesses dos empresários participantes.

As relações interorganizacionais podem não compensar os investimentos realizados para alguns empresários, o que é, aparentemente, ocasionado pelos aspectos e fatores encontrados neste trabalho, que dificultam a satisfação dos interesses de todos os integrantes. Estes, mesmo que haja uma avaliação objetiva e mensurável dos resultados que a rede pode proporcionar, estabelecem uma relação custo $\mathrm{x}$ benefício para decidir entre permanecer ou não na rede. $\mathrm{O}$ estudo, no que tange a esse assunto de redes, remete a algumas questões como: a aparente inobservância ou inexistência de critérios de seleção dos parceiros é um fator que condicionou outros aspectos negativos (problemas) para as redes? Até que ponto as empresas estão dispostas a investir em redes?

Estudos que avancem nessas questões devem ser desenvolvidos para aumentar a compreensão sobre o assunto e as possibilidades de sucesso desse tipo de empreendimento, em especial, no que diz respeito àqueles formados por empresas de pequeno porte, que geralmente possuem maiores dificuldades na gestão de suas atividades. Quanto às limitações do estudo, tem-se como a principal delas o fato de ser baseado apenas na percepção dos presidentes das redes pesquisadas. A sugestão é a de que novos trabalhos sejam desenvolvidos verificando a percepção de empresários que decidiram sair de redes. Estudos em ramos de atividades distintos poderiam lançar luz sobre outras variáveis e aspectos específicos sobre cada área de atuação das redes (ex.: mercados, padarias, materiais de 
construção...), visando solidificar um arcabouço teórico a respeito do fenômeno.

\section{REFERÊNCIAS}

ADLER, P., KWON, S.-W. (2002). Social capital: Prospects for a new concept. Academy of Management Review, 23 (1): 15-22.

AHOLA, T. (2009). Efficiency in Project Networks: The role of inter-organizational relationships in project implementation. Helsinki, Finland (Doctoral Thesis). Helsinki University of Technology, $248 \mathrm{p}$.

AHUJA, G.; SODA, G.; ZAHEER, A. (2012). The Genesis and Dynamics of Organizational Networks. Organization Science, 23 (2): 434-448.

ANDRÉSEN, E., LUNDBERG, H., ROXENHALL, T. (2012). Designing for commitment in regional strategic networks. Management Research Review, 35 (6): 531-552.

BACHMANN, R. (2011). At the crossroads: Future directions in trust research. Journal of Trust Research 1, 203-213.

BACHMANN, R., KNIGHTS, D., SYDOW, J. (2001). Trust and control in organizational relations. Organization Studies, 22 (2): 337-365.

BARDIN, L. (2010). Análise de Conteúdo, 6. ed. Lisboa: Edições 70 Ltda., 281 p.

BINGHAM, L. B., O'LEARY, R. (2008). Big Ideas in Collaborative Public Management. Armon, NY, ME Sharpe, 288p.

BRITTEN, N. (1995). Qualitative Research: Qualitative interviews in medical research. British Medical Journal, 311: 251-253.

CARDOSO, L., MEIRELES, A. AND PERALTA, C.F. (2012). Knowledge management and its critical factors in social economy organizations. Journal of Knowledge Management, 16 (2): 267-284.

CASTRO, M., BULGACOV, S., HOFFMANN, V. E. (2011). Relacionamentos Interorganizacionais e Resultados: Estudo em uma Rede de Cooperação Horizontal da Região Central do Paraná. Revista de Administração Contemporânea (RAC), 15 (1): 25-46.

CHAO, Y.-C. (2011). Decision-making biases in the alliance life cycle: Implications for alliance failure. Management Decision, 49 (3): 350-364.

CHASSAGNON, V. (2013). Consummate cooperation in the network-firm: Theoretical insights and empirical findings. European Management Journal, 32 (2): 260-274.

CHEN, B. (2010). Antecedents or Processes? Determinants of Perceived Effectiveness of Interorganizational Collaborations for Public Service Delivery. International Public Management Journal, 13 (4): 381-407.

CORSTEN, D., GRUEN, T., PEYINGAUS, M. (2011). The effects of supplier-to-buyer identification on operational performance - An empirical investigation of inter-organizational identification in automotive relationships. Journal of Operations Management, 29: 549-560. 
DENZIN, N. K., LINCOLN Y. S. (2006). O Planejamento da Pesquisa Qualitativa: teorias e abordagens. Porto Alegre: Artmed, 432p.

DOZ, L. Y. (1996). The Evolution of Cooperation in Strategic Alliances: Initial Conditions or Learning Processes? Strategic Management Journal, 17 (Special Issue): 55-83.

EBERS, M. (1999). Explaining interorganizational network formation. In: M. EBERS. The formation of inter-organizational networks. New York: Oxford University Press, p. 3-40.

EISENHARDT, K. M. (1989). Building theories from case study research. The Academy of Management Review, 14 (4): 532.

ENGESTRÖM, Y., KEROSUO, H. (2007). From workplace learning to inter-organizational learning and back: The contribution of activity theory. Journal of Workplace Learning, 19 (6): 336-342.

FLEURY, M. T. L., OLIVEIRA, M. M., Jr. (2001). (Coord.). Gestão estratégica do conhecimento: integrando aprendizagem, conhecimento e competências, 1. ed. São Paulo: Atlas, 352p.

GRADDY, E., CHEN, B. (2006). Influences on the Size and Scope of Networks for Social Service Delivery. Journal of Public Administration Research and Theory, 16 (4): 533-552.

GULATI, R. (1995). Does Familiarity Breed Trust? The Implications of Repeated Ties for Contractual Choice in Alliances. Academy of Management Journal, 38 (1): 85-112.

GULATI, R. (2007). Silo Busting: Transcending Barriers to Build High Growth Organizations. Harvard Business Review, 85 (5): 98-108.

GULATI, R., GARGIULO, M. (1999). Where do interorganizational networks come from? American Journal of Sociology, 104 (5): 1.439-1.493.

HITT, M. A., LEVITAS, E., ARREGLE, J., BORZA, A. (2000). Partner Selection in Emerging and Developed Market Contexts: Resource-Based and Organizational Learning Perspectives. Academy of Management Journal, 43: 449-467.

HOBERECHT, S., JOSEPH, B., SPENCER, J., SOUTHERN, N. (2011). Inter-organizational networks: An emerging paradigm of whole systems change. OD Practitioner, 43 (4): 23-27.

IRELAND, R. D., WEBB, J. W. (2007). A cross-disciplinary exploration of entrepreneurship research. Journal of Management, 33 (6): 891-927.

LAMB, C., HAIR, J. F., MCDANIEL, C. (2008). Marketing, 9. ed. Cincinnati: OH, Southwestern Publishing.

LANGLOIS, R. N., ROBERTSON, P. L. (1995). Firms, Markets and Economic Change: a dynamic theory of business institutions. London: Routlege, $200 \mathrm{p}$.

LIN, Z. J., YANG, H., ARYA, B. (2009). Alliance partners and firm performance: resource complementarily and status association. Strategic Management Journal, 30: 921-940.

MARIOTTI, F.; DELBRIDGE, R. (2012). Overcoming network overload and redundancy in interorganizational networks: The role of potential and latent ties. Organization Science, 23 (2): 511-528. 
MCCUTCHEN, W.W., JR., SWAMIDASS, P. M., TENG, B.-S. (2008). Strategic alliance termination and performance: The role of task complexity, nationality, and experience. Journal of High Technology Management Research, 18: 191-202.

MISHRA, D. P., HEIDE J. B., CORT, S. G. (1998). Information Asymmetry and Levels of Agency Relationships. Journal of Marketing Research, 35: 277-295.

MPOYI, R. (2003, April). The Impact of Industry Characteristics on Vertical Integration Strategies. International Academy of Business and Economics Annual Meeting. Orlando, FL, United States.

NICOTRA, M., ROMANO, M., DEL GIUDICE, M. (2014). The evolution dynamic of a cluster knowledge network: the role of firms' absorptive capacity. Journal of the Knowledge Economy, 5 (2): 240-264.

OLIVER, C. (1990). Determinants of interorganizational relationships: integration and future directions. Academy of Management Review, 15 (2): 241-265.

OYSERMAN, D., COON, H. M., KEMMELMEIER, M. (2002). Rethinking individualism and collectivism: evaluation of theoretical assumptions and meta-analyses. Psychological Bulletin, 128: 3-72.

PARAST, M. M., DIGMAN, L. A. (2008). Learning: the interface of quality management and strategic alliances. International Journal of Production Economics, 114 (2): 820-829.

PARK, S. H., UNGSON, G. R. (2001). Inter-firm Rivalry and Managerial Complexity: a conceptual framework of alliance failure. Organization Science, 12 (1): 37-53.

PEREIRA, B. A. D. (2005). Estruturação de Relacionamentos Horizontais em Rede. Porto Alegre, RS (Tese de Doutorado). Escola de Administração, Universidade Federal do Rio Grande do Sul - UFRGS, Brasil, 218 p.

PEREIRA, B. A. D.; PEDROZO, E. A. (2004). O outro lado da cooperação: uma análise dos problemas na gestão das redes interorganizacionais. In: J. R. S. Verschoore (Org.). Redes de Cooperação: uma nova organização de pequenas e médias empresas no Rio Grande do Sul, 1. ed. Porto Alegre: Fundação de Economia e Estatística, p. 49-68.

PEREIRA, B. A. D., VENTURINI, J. C., WEGNER, D., BRAGA, A. L. (2010). Desistência da cooperação e encerramento de redes interorganizacionais: em que momento essas abordagens se encontram? RAI - Revista de Administração e Inovação, 7 (1): 62-83.

PESÄMAA, O. (2007). Development of relationships in interorganizational networks: Studies in the tourism and construction industries. Strömsund, Sweden (Unpublished Doctor's thesis) Luleå University of Technology, $303 \mathrm{p}$.

PHELPS, C., HEIDL, R., WADHWA, A. (2012). Knowledge, networks, and knowledge networks: A review and research agenda. Journal of Management, 38 (4): 1.115-1.166.

RAAB, J., MANNAK, R. S., CAMBRE, B. (2013). Combining Structure, Governance, and Context: A Configurational Approach to Network Effectiveness. Journal of Public Administration Research and Theory, 23: 1-33.

RICHARDSON, R. J. (1999). Pesquisa social: métodos e técnicas, 3. ed. São Paulo: Atlas, 336 p. 
SADOWSKI, B., DUYSTERS, G. (2008). Strategic technology alliance termination: An empirical investigation. Journal of Engineering and Technology Management, 25 (4): 305-320.

SAMPIERI, R. H., COLLADO, C. F., LUCIO, P. B. (2006). Metodologia de Pesquisa. São Paulo: McGrall-hill Interamericana do Brasil Ltda.

SCHULZ, K., GEITHNER, S. (2010). Between exchange and development: Organizational learning in schools through inter-organizational networks. Learning Organization, 17 (1): 69-85.

SELLTIZ, C., WRIGHTSMAN, L. S., COOK, S. W. (1972). Métodos de pesquisa nas relações sociais, 1. ed. São Paulo: Herder, 118p.

SHENG-YUE, H.; XU, R. (2005). Analyses of strategic alliance failure: a dynamic model. International Conference on Management Science and Engineering. Incheon, South Korea.

TRIVIÑOS, A. N. S. (1987). Introdução a Pesquisa em Ciências Sociais: a pesquisa qualitativa em educação, 1. ed. São Paulo: Atlas, 176 p.

VAN SLYKE, D. M. (2007). Agents or Stewards: Using Theory to Understand the Government Nonprofit Social Service Contracting Relationship. Journal of Public Administration Research and Theory, 17 (2): 157-187.

VENTURINI, J. C. (2008). Assimetria de informação em redes de empresas horizontais: um estudo das diferentes percepções de seus atores. Santa Maria, RS (Dissertação de Mestrado). Universidade Federal de Santa Maria (UFSM), Brasil, 148 p.

VERSCHOORE, J. R. S. (2004). Redes de Cooperação: concepções teóricas e verificações empíricas. In: J. R. S. VERSCHOORE. (Org.). Redes de Cooperação: uma nova organização de pequenas e médias empresas no Rio Grande do Sul, 1. ed. Porto Alegre: Fundação de Economia e Estatística, p. 70-88.

VINHAS, A. S., HEIDE, J B., JAP, S. D. (2012). Consistency Judgments, Embeddedness, and Relationship Outcomes in Interorganizational Networks. Management Science, 58: 996-1.011.

WEGNER, D. (2011). Governança, Gestão e Capital Social em redes interorganizacionais de empresas: uma análise de suas relações com o desempenho das empresas participantes. Porto Alegre, RS (Tese de Doutorado). Escola de Administração, Universidade Federal do Rio Grande do Sul - UFRGS, Brasil, 203 p.

WEGNER, D., PADULA, A. D. (2010). Governance and Management of Horizontal Business Networks: An Analysis of Retail Networks in Germany. International Journal of Business and Management, 5 (12): 74-88.

WEGNER, D., PADULA, A. D. (2012). Quando a cooperação falha: um estudo de caso sobre o fracasso de uma rede interorganizacional. Revista Administração Mackenzie (RAM), 13 (1): 145-171.

WEGNER, D., ZEN, A. C., ANDINO, B. F. A. (2008, outubro). O Último que Sair Apaga as Luzes: Motivos para a desistência da cooperação interorganizacional e o encerramento de redes de empresas. XI SEMEAD - Seminário de Administração. São Paulo, SP, Brasil.

WELTER, F. (2012). All you need is trust? A critical review of the trust and entrepreneurship literature. International Small Business Journal, 30 (3): 193-212. 
WILLIANSON, O. E. (1975). Market and hierarchies: analysis and antitrust implications, 1. ed. New York: Free Press, 286 p.

WILLIANSON, O. E. (1985). The economic institutions of capitalism, 1. ed. New York: Free Press, $468 \mathrm{p}$.

WINCENT, J., THORGREN, S., ANOKHIN, S. (2014). Entrepreneurial orientation and network board diversity in network organizations. Journal of Business Venturing, 29: 327-344.

YAYAVARAM, S., AHUJA, G. (2008). Decomposability in knowledge structures and its impact on the usefulness of inventions and knowledge-base malleability. Administrative Science Quarterly, 53: 333-362.

YU, S-H., CHEN, M-Y. (2013). Performance impacts of interorganizational cooperation: a transaction cost perspective. The Service Industries Journal, 33(13-14): 1.223-1.241.

ZAWISLAK, P. A. (2000). Alianças Estratégicas: contexto e conceitos para um modelo de gestão. Saberes, 1 (3): 10-21.

ZINELDIN, M., DODOUROVA, M. (2005). Motivation, achievements and failure of strategic alliances: The case of Swedish auto-manufacturers in Russia. European Business Review, 17 (5): $460-470$.

Recebido em: 22-4-2017

Aprovado em: 4-9-2017

Avaliado pelo sistema double blind review.

Editor: Coordenação do PPGA/UMESP

Disponível em http://mjs.metodista.br/index.php/roc 